\title{
'White coat, warm heART'
}

Previously published at www.cmaj.ca

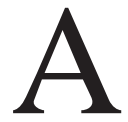
rt appears to have found a home in the halls of Canadian medical institutions. Sixty health science students, residents, and faculty from across Canada, submitted art to a juried show held in conjunction with the 2010 Canadian Conference of Medical Education, which celebrated the integration of science, arts and humanities.

Seventeen pieces were selected for the exhibit, White coat, warm heART, at the conference in May in St. John's, Newfoundland by a jury that included Dr. Ruth Martin, Pamela BrettMcLean, Pat Grattan (the former curator of National Museum of Art in Newfoundland and Labrador), Barbara Sibbald and Carol-Ann Courneya.

According to organizer Courneya, the exhibit had three aims: to bear wit- ness to the creative visions of our colleagues; to be more fully present in the midst of teaching and learning and caring; and to consider the deep current of creativity and artistic visions that contribute to the field of medical education.

CMAJ presents three of these works, along with excerpts from the artists' statements. - CMAJ

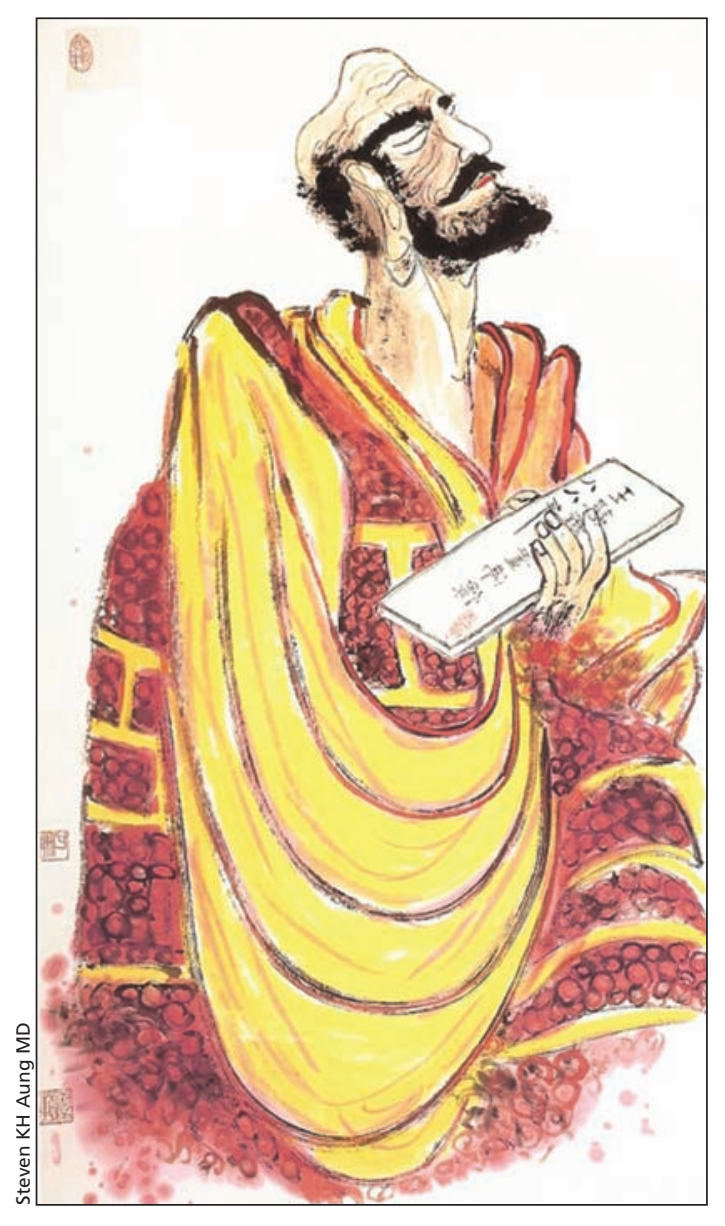

The Great Buddhist Physician Healer: U Saw Pe Ta (2001). Chinese colourful ink on paper. $107 \times$ $213 \mathrm{~cm}$. U Saw Pe Ta was an imminent physician in ancient times, well known as an extraordinary and gifted healer.

\section{The Great Buddhist Physician Healer: U Saw Pe Ta}

Dr. Steven KH Aung works in family, geriatric and integrated medicine, and teaches at the University of Alberta, Edmonton, Alta. He received the Order of Canada 2006, is the World Health Organization's advisor on traditional Chinese medicine and has written several articles and books on various aspects of traditional Chinese medicine as well as Chinese calligraphy and painting.

Artist's statement: I have been involved in traditional Chinese brush painting and calligraphy since I was a child, under the loving guidance of my father and grandfather, and later under Taoist and Buddhist masters. I am primarily interested in creating large spiritual paintings and calligraphic works expressing aspects of Taoist and Buddhist philosophy.

Being artistically creative has profoundly increased my well-being. I have much more balance in life and my well-being is put into harmony quickly, reliably, and gently. Artistic creativity makes me feel more integrated in terms of body, mind and spirit. Like a poet I am completely and utterly in the moment and absorbed when I work on art.

My experience making art has also had a positive influence on my professional work. It has helped me to heal my patients rather than just treat the illness or disease. The time spent creating art has also helped me maintain the healing energy and focus that is necessary for the long days I spend solving complex clinical problems. In addition, creating art has given me more insight into the nature of healing, suffering and spirituality (www.aung.com). 


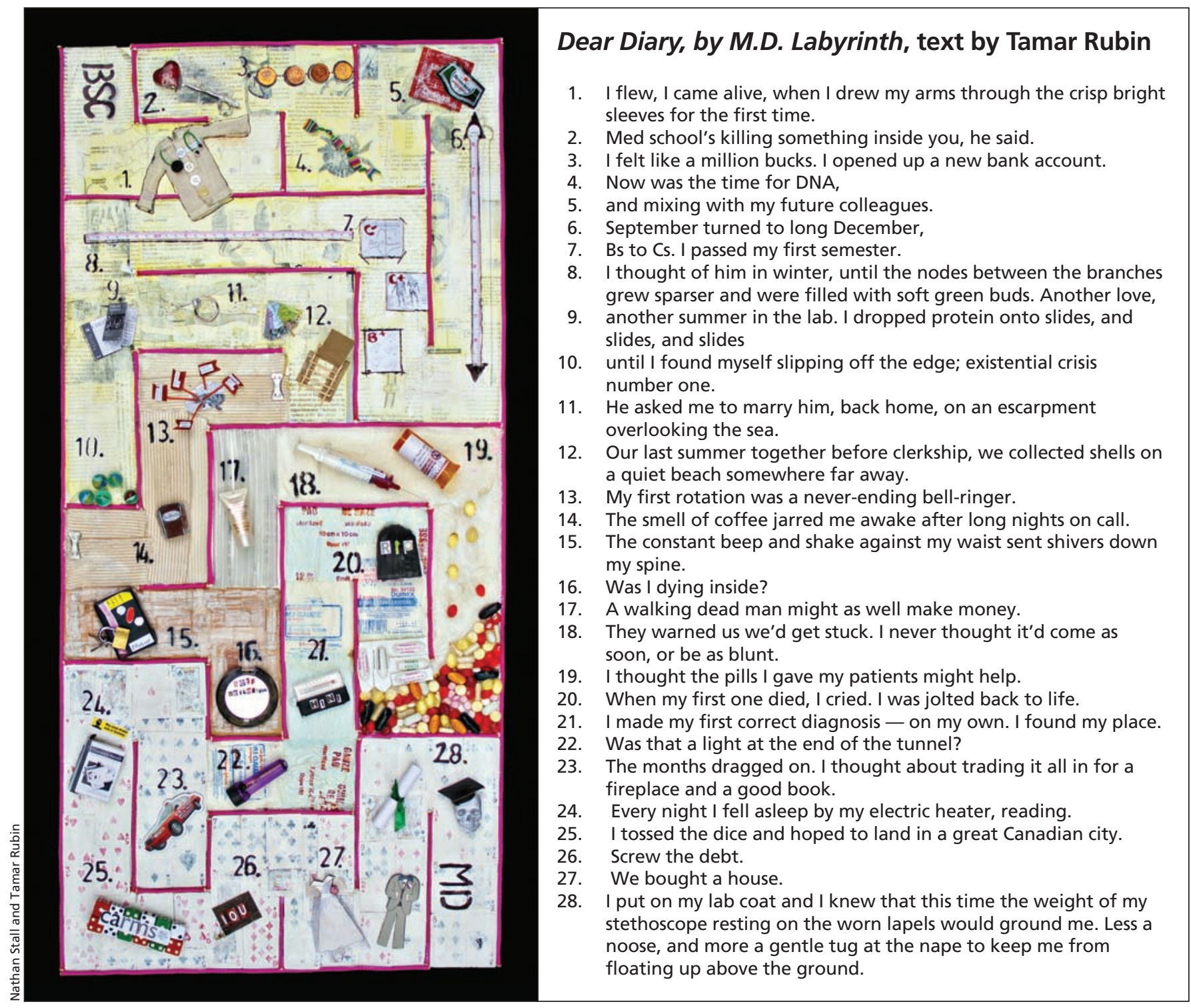

Dear Diary, by M.D. Labyrinth (2009-10), mixed media. $46 \times 96 \mathrm{~cm}$. The text, to the right, appears in the art work.

\section{Dear Diary, by M.D. Labyrinth}

This art piece was created by the couple Nathan Stall and Tamar Rubin, who are both medical students. Stall studies at the University of Western Ontario in London, Ont., while Rubin attends the University of Toronto, Toronto, Ont.

Artists' statement: During our medical training, we are taught how to tell patients' stories. In this process we are encouraged to pare down their rich narratives and present a concise and accurate medical vignette - the "case report." Unfortunately due to this process we lose a fascinating and essential dimension of the "big picture" that initially drew us to medicine. Furthermore, the medical student's personal narrative is mostly irrelevant, and therefore largely untold.

As two reflective medical students, we have found that artistic endeavors are an essential aspect of our personal medical education. Through our work we are able to tell the story of our medical training, sort out the challenges we face and make meaning out of our varied experiences.

It seems as though we are often expressing our frustration and disillusionment with medicine and medical education in our art. However, by own- ing these feelings, and working through them at every stage of training, we believe we can help avert becoming jaded and "building up walls" between ourselves and our patients, something that plagues so many in medicine.

For us, art is not only an opportunity to reflect, but also an opportunity to spend time together. As a couple with busy schedules, engaged in a longdistance relationship, making time for fun and extracurricular activities is important. We are both creative: Nathan studied art history at McGill, and Tamar, the daughter of an artist, is an avid writer in her spare time. Creating art is one way we continue to unleash that creativity. 


\section{An empathetic and benevolent heart}

Charmaine Ma BSc (Pharm), is a medical student in the class of 2013 at the University of British Columbia, Vancouver, BC.

Artist's statement: The Chinese character for heart dates to before $1200 \mathrm{BC}$ (writings on oracle bone) and is a pictogram of the anatomical heart, depicting its four chambers and the flow of blood from the right atrium to the aorta. This character is a scientific and anatomic description of the heart, but it is also the artistic foundation of other Chinese characters such as love, which has the heart in its centre.

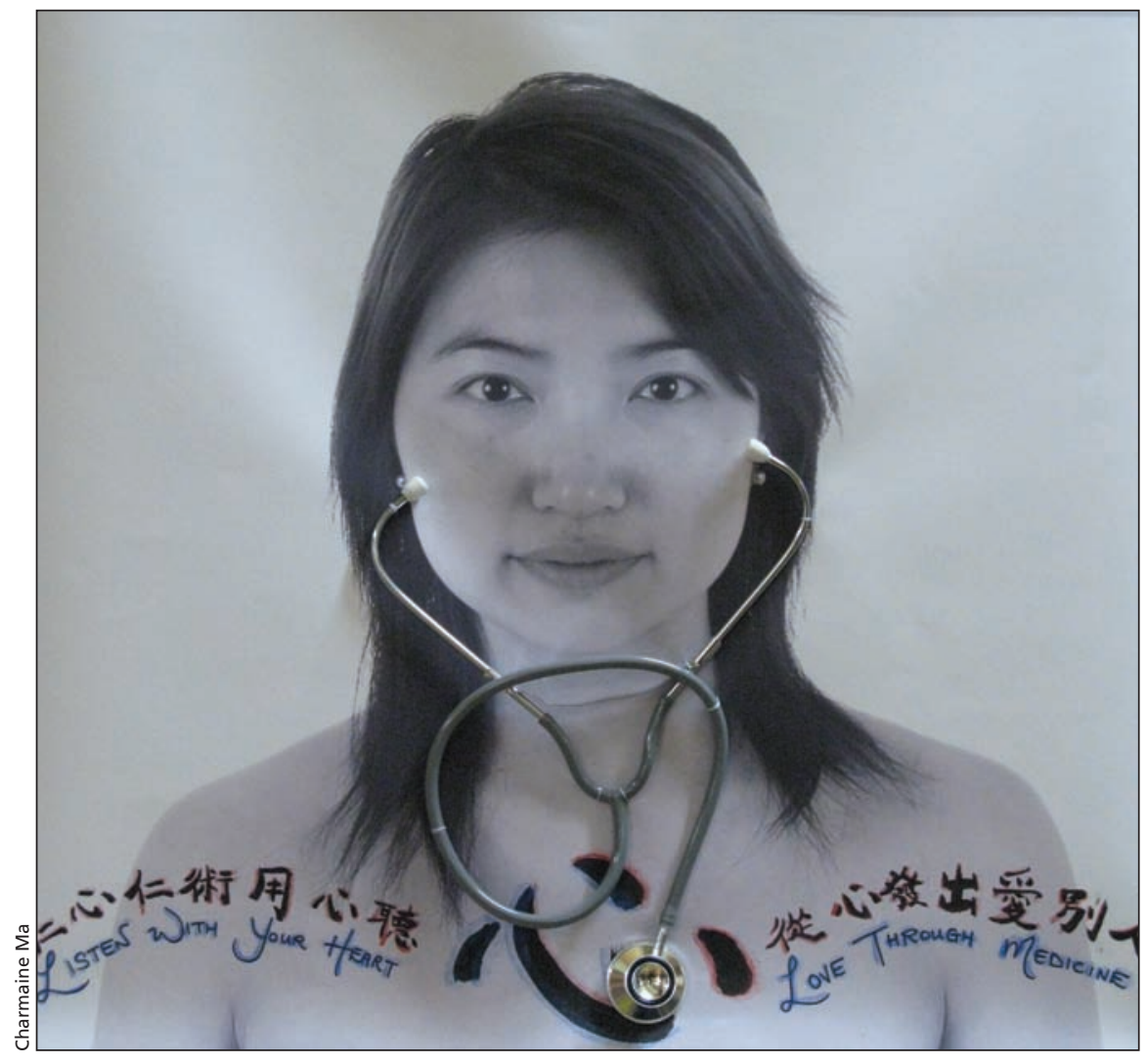

An empathetic and benevolent heart (2010), digitally printed on silk banner. $68 \times 97 \mathrm{~cm}$.
There is a Chinese proverb that states that empathetic and benevolent medicine can only be accomplished through an empathetic and benevolent heart. These four characters that make up this proverb are usually written on plaques or calligraphy pieces and given to newly practising physicians from patients and elders to hang in the office to encourage them and remind them of this premise.

Listening to our patients is an integral part of practice and listening involves not simply the ears but, more importantly, our hearts. A sincere and genuine heart is the beginning and end of medicine. Despite the many modern technological advances and evidence-based medicine we cannot forget that we are ultimately human. Medicine is a demonstration of love for humankind, curiosity for cure and a hope for the future.

As a young medical student I assume that all physicians entered this profession in the hope of genuinely helping others. Unfortunately our long training, heavy demands and busy schedules make even the keenest students dread the long on-call hours or extra patient at $3 \mathrm{am}$. For this reason, I constantly try to remind myself that empathetic and benevolent medicine can only be done through an empathetic and benevolent heart. 